\title{
Preeclampsia knowledge among postpartum women treated for preeclampsia and eclampsia at Korle Bu Teaching Hospital in Accra, Ghana
}

\author{
Avina Joshi ${ }^{1}$, Titus Beyuo ${ }^{2,3^{*}}$ (D), Samuel A. Oppong ${ }^{2,3}$, Cheryl A. Moyer ${ }^{4,5}$ and Emma R. Lawrence ${ }^{5}$
}

\begin{abstract}
Background: Preeclampsia/eclampsia is a major cause of maternal morbidity and mortality worldwide, yet patients' perspectives about their diagnosis are not well understood. Our study examines patient knowledge among women with preeclampsia/eclampsia in a large urban hospital in Ghana.

Methods: Postpartum women diagnosed with preeclampsia or eclampsia were asked to complete a survey 2-5 days after delivery that assessed demographic information, key obstetric factors, and questions regarding provider counseling. Provider counseling on diagnosis, causes, complications, and future health effects of preeclampsia/ eclampsia was quantified on a 4-point scale ('Counseling Composite Score'). Participants also completed an objective knowledge assessment regarding preeclampsia/eclampsia, scored from 0 to 22 points ('Preeclampsia/ Eclampsia Knowledge Score' (PEKS)). Linear regression was used to identify predictors of knowledge score.

Results: A total of 150 participants were recruited, 88.7\% (133) with preeclampsia and $11.3 \%$ (17) with eclampsia. Participants had a median age of 32 years, median parity of 2 , and mean number of 5.4 antenatal visits. Approximately half of participants reported primary education as their highest level of education. While $74 \%$ of women reported having a complication during pregnancy, only $32 \%$ of participants with preeclampsia were able to correctly identify their diagnosis, and no participants diagnosed with eclampsia could correctly identify their diagnosis. Thirty-one percent of participants reported receiving no counseling from providers, and only $11 \%$ received counseling in all four categories. Even when counseled, 40-50\% of participants reported incomplete understanding. Out of 22 possible points on a cumulative knowledge assessment scale, participants had a mean score of $12.9 \pm 0.38$. Adjusting for age, parity, and the number of antenatal visits, higher scores on the knowledge assessment are associated with more provider counseling ( $\beta$ 1.4, SE 0.3, $p<0.001)$ and higher level of education $(\beta$ 1.3$, SE $0.48, p=0.008)$.

* Correspondence: drbeyuo@gmail.com

${ }^{2}$ University of Ghana School of Medicine and Dentistry, Slater Avenue, Accra,

Ghana

${ }^{3}$ Department of Obstetrics \& Gynaecology, Korle Bu Teaching Hospital, Guggisberg Avenue, Accra, Ghana

Full list of author information is available at the end of the article

(c) The Author(s). 2020 Open Access This article is licensed under a Creative Commons Attribution 4.0 International License, which permits use, sharing, adaptation, distribution and reproduction in any medium or format, as long as you give appropriate credit to the original author(s) and the source, provide a link to the Creative Commons licence, and indicate if changes were made. The images or other third party material in this article are included in the article's Creative Commons licence, unless indicated otherwise in a credit line to the material. If material is not included in the article's Creative Commons licence and your intended use is not permitted by statutory regulation or exceeds the permitted use, you will need to obtain permission directly from the copyright holder. To view a copy of this licence, visit http://creativecommons.org/licenses/by/4.0/ The Creative Commons Public Domain Dedication waiver (http://creativecommons.org/publicdomain/zero/1.0/) applies to the data made available in this article, unless otherwise stated in a credit line to the data. 
(Continued from previous page)

Conclusions: Counseling by healthcare providers is associated with higher performance on a knowledge assessment about preeclampsia/eclampsia. Patient knowledge about preeclampsia/eclampsia is important for efforts to encourage informed healthcare decisions, promote early antenatal care, and improve self-recognition of warning signs-ultimately improving morbidity and reducing mortality.

Keywords: Maternal health, Pregnancy, Preeclampsia, Eclampsia, Patient knowledge, Patient education, Provider counseling, Sub-Saharan Africa

\section{Background}

Preeclampsia and eclampsia are leading causes of maternal morbidity and mortality [1]. The burden of preeclampsia and eclampsia is most significant in low- and middle-income countries (LMICs), where hypertensive disorders of pregnancy account for $10-15 \%$ of maternal deaths $[1,2]$. In many LMICs, including the West African country of Ghana, hypertensive disorders of pregnancy have overtaken hemorrhage as the leading cause of maternal mortality [3, 4].

In pregnancies complicated by preeclampsia and eclampsia, improved outcomes are seen with early identification of symptoms, prompt presentation to healthcare facilities, and subsequent management with antihypertensive medications, magnesium sulfate, and delivery of the fetus and placenta [2, 5-8]. Development of preeclampsia or eclampsia is a significant risk factor for recurrence in subsequent pregnancies [7]. Since preeclampsia and eclampsia are exclusively complications of pregnancy, antenatal care (ANC) visits and intrapartum admission are important opportunities for patient counseling $[9,10]$. Prenatal education on symptoms of preeclampsia and eclampsia may result in improved outcomes [11-14], with studies linking understanding of counseling to higher rates of women taking action and reporting symptoms [15].

Despite the important connections between women's knowledge of warning signs and seeking appropriate care, little research has addressed the patient perspective. Studies conducted in high-income countries demonstrate that only half of patients were counseled on signs and symptoms of preeclampsia [16], even though counseling by healthcare providers is associated with increased patient knowledge [16-18].

In LMICs, healthcare providers and patients face unique challenges, including lower general education levels and health literacy, and limited access and utilization of antenatal care services [19, 20]. Previous research in Ghana [17], Tanzania [21, 22], and Malaysia [23] all demonstrate low levels of knowledge about preeclampsia among pregnant women. However, none of these studies focused on women with a clinical diagnosis of preeclampsia or eclampsia.

A better understanding of a patient's knowledge about her diagnosis and implications for future pregnancies is important when caring for high-risk women. However, the experience and knowledge of women with preeclampsia and eclampsia in LMICs is largely unknown. The current study fills this gap-evaluating counseling, understanding, and knowledge of postpartum women diagnosed with preeclampsia and eclampsia in a large urban tertiary hospital in Ghana.

\section{Methods}

This study took place at the Korle $\mathrm{Bu}$ Teaching Hospital (KBTH), Ghana's largest tertiary care hospital located in the capital city of Accra. The maternity unit serves patients receiving antenatal care at $\mathrm{KBTH}$ and referral cases from the southern half of the country, with approximately 9500 deliveries per year.

Ethical approval was granted by the Scientific and Technical Committee of the Korle Bu Teaching Hospital (KBTH-IRB 00096/2018) and the University of Michigan Institutional Review Board (HUM00139104). Study participants were identified through the ongoing MOPEP Trial, a randomized controlled trial of comparative dosing regimens of magnesium sulfate for management of preeclampsia and eclampsia [24]. Inclusion criteria were admission to KBTH with a diagnosis of eclampsia or preeclampsia with severe features, age 18 years or older, and fluency in English or Twi/Akan.

Data collection was completed between November 2019 and March 2020 by two research assistants, one of whom was fluent in Twi/Akan. Eligible participants were recruited in the postpartum inpatient ward at least 2 days after delivery, and a written informed consent process was completed. A standardized survey was verbally administered by a research assistant. Surveys were completed at the bedside in the language choice of the participant. See Additional file 1 for the complete survey questions.

Demographic information and obstetric history were collected from the participants' clinical charts. The survey consisted of two parts. Part I (24 questions) focused on patient perceptions of provider counseling about their clinical diagnosis. This section assessed the recollection and comprehension of information provided by the healthcare provider on four counseling categories: diagnosis, causes, possible complications, and future health effects, including likelihood of recurrence in 
future pregnancies. A counseling composite score was created ranging from 0 to 4 possible points, where one point was awarded for a participant responding 'Yes' to being counseled on any of the four categories. Participants who responded 'Yes' to being counseled on any of these four categories were then asked a follow-up question regarding their perceived level of understanding of the counseling. Understanding was graded on a 4-point scale: None, Some, Most, or All. The interviewer explained that 'Some' meant understanding less than half of the information provided, while 'Most' meant understanding more than half. During data analysis, 'Less than $50 \%$ Understanding' was defined as a response of 'None' or 'Some' and 'More than 50\% Understanding' was defined as a response of 'Most' or 'All.'

Part II (10 questions) was an objective knowledge assessment, adapted to the local Ghanaian context from a survey developed by the Preeclampsia Foundation [16]. Participants were asked multiple choice and true/false questions about risk factors, symptoms, and management of preeclampsia. Responses were summed to generate a cumulative Preeclampsia/Eclampsia Knowledge Score (PEKS), with a total of 22 possible points. This cumulative knowledge score was used as the primary outcome variable.

Surveys were completed via pen and paper, entered into REDCap, and downloaded into STATA (Version 16.0 StataCorp. 2019) for cleaning and analysis. Descriptive statistics were calculated for all key variables using medians (minimum/maximum range) and frequencies (proportion). Bivariate linear regression analysis was used to evaluate the relationship between the PEKS, demographic and clinical factors, and counseling indicators. Significant variables in our bivariate model were included in a multivariate linear regression analysis, which was also adjusted by age, parity, and number of antenatal visits, as these are often linked to knowledge of pregnancy-related factors. All tests were two-tailed and a $p$ value of $<0.05$ was accepted as significant.

\section{Results}

From November 2019-March 2020, a total of 150 participants completed the study (Fig. 1). Table 1 illustrates participant demographics. Participants had a median age of 32 years (range 18-47) and 63.3\% (95) were multiparous. Approximately half (70) of participants reported

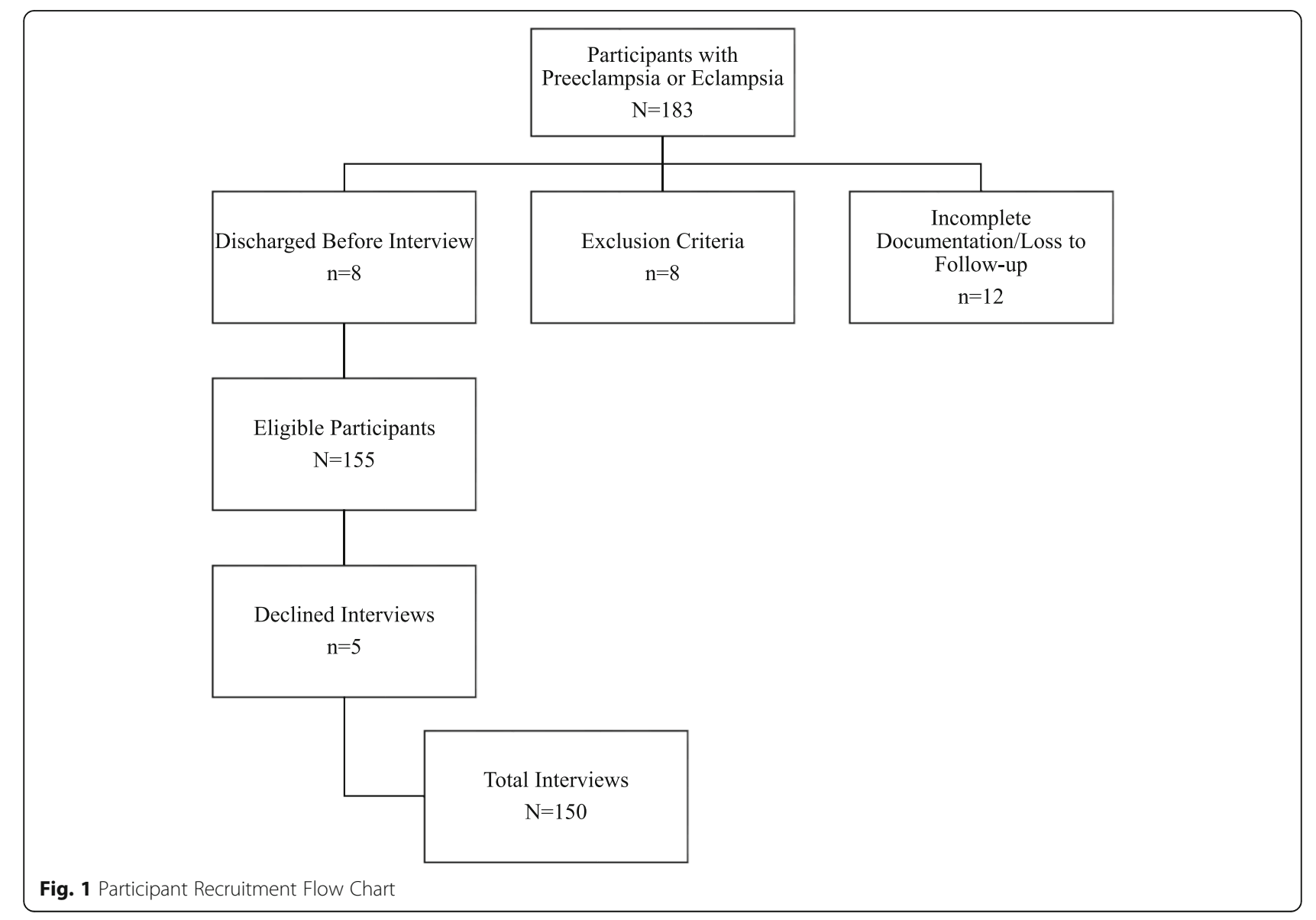


Table 1 Demographic Factors

\begin{tabular}{|c|c|}
\hline Characteristic & Participants $(n=150)$ \\
\hline Age, years ${ }^{a}$ & $32(18-47)$ \\
\hline \multicolumn{2}{|l|}{ Participant Reported Language Used for Healthcare } \\
\hline English & $33(22.0)$ \\
\hline Twi & $117(78.0)$ \\
\hline \multicolumn{2}{|l|}{ Highest Level of Completed Education } \\
\hline None & $1(0.7)$ \\
\hline Primary & $70(47.0)$ \\
\hline Secondary & $39(26.2)$ \\
\hline Tertiary & $39(26.2)$ \\
\hline \multicolumn{2}{|l|}{ Clinical Diagnosis } \\
\hline Preeclampsia & $133(88.7)$ \\
\hline Eclampsia & $17(11.3)$ \\
\hline Parity $^{a}$ & $2(1-10)$ \\
\hline Primiparous & $55(36.7)$ \\
\hline Multiparous & $95(63.3)$ \\
\hline \multicolumn{2}{|l|}{ Primary Caregiver During Pregnancy } \\
\hline Specialist obstetrician/gynecologist & $42(29.2)$ \\
\hline Medical officer (non-obstetrician) & $9(6.0)$ \\
\hline Midwife & $90(60.4)$ \\
\hline Other & $1(0.7)$ \\
\hline None & $7(4.7)$ \\
\hline Number of Antenatal Appointments Attended ${ }^{a}$ & $5.3(0-14)$ \\
\hline $0-3$ & $42(28.0)$ \\
\hline$\geq 4$ & $108(72.0)$ \\
\hline \multicolumn{2}{|c|}{ Diagnosis of Chronic Hypertension (index pregnancy) } \\
\hline Yes & $33(22.0)$ \\
\hline No & $117(78.0)$ \\
\hline \multicolumn{2}{|c|}{ Previous Hypertensive Disorder of Pregnancy (previous pregnancies) } \\
\hline Preeclampsia/Eclampsia & $10(6.7)$ \\
\hline Gestational hypertension & $11(7.3)$ \\
\hline
\end{tabular}

Data presented as $\mathrm{n}(\%)$ unless otherwise noted

${ }^{a}$ Median (range: minimum value - maximum value)

their highest completed level of education as 'Primary.' A majority $(133,88.7 \%)$ of participants were diagnosed with preeclampsia, while $17(11.3 \%)$ participants were diagnosed with eclampsia. Regarding history of hypertensive disorders of pregnancy, 33 (22.0\%) participants had a comorbid diagnosis of chronic hypertension, 10 (6.7\%) had preeclampsia/eclampsia in a prior pregnancy, and 11 (7.3\%) had gestational hypertension in a prior pregnancy. Most women received care from a midwife $(90,60.4 \%)$, attended four or more antenatal visits $(108,72 \%)$, and conducted their healthcare communication primarily in Twi/Akan (117, 78\%).
Figure 2 illustrates participant responses regarding their understanding of their diagnosis. Only $24 \%$ of participants with preeclampsia correctly identified their diagnosis, and none of the participants with eclampsia were able to correctly identify their diagnosis. Additionally, $86(61.4 \%)$ participants reported never hearing about preeclampsia/eclampsia during their pregnancy. While $74 \%$ of participants correctly identified the severity of preeclampsia/eclampsia as very serious, almost two-thirds of participants (92, 62\%) said they do not understand it well enough to explain it to another person and 73\% (108) said they do not know what to do in future pregnancies to prevent the condition or improve its outcome (Table 2).

Figure 3 shows participant perceptions of provider counseling. Eighty-eight (58.7\%) women said they received an explanation from a healthcare provider about their diagnosis, 40 (26.7\%) about causes of the condition, 74 (49.3\%) about complications, and 35 (23.3\%) about future health effects. Of those who reported receiving counseling on these topics, $44.0 \%$ of women who received information about their diagnosis, $50 \%$ who received information about the causes, $39.2 \%$ who received information about potential complications, and $42.9 \%$ who received information about future health effects said they understood less than half of information provided. Figure 4 illustrates the 'Counseling Composite' Score for participants. The largest proportion of participants $(47,31.3 \%)$ did not receive counseling on any of the four categories.

Out of 22 possible points on the PEKS, participants scored a mean of 13 (SD 4.5) with a range of 2-21. Table 3 demonstrates bivariate linear regression, evaluating the relationship between the PEKS and demographics, obstetric factors, and perceived level of counseling. Variables significantly associated with PEKS included language used for healthcare, level of education, comorbid chronic hypertension, and history of preeclampsia/eclampsia in a previous pregnancy. Patient-reported provider counseling in each of the four categories, as well as the composite counseling score, were also significant. After adjusting for age, parity, and number of attended antenatal visits, higher level of education and a higher counseling composite score were significant contributors to a participant's PEKS (Table 4). Each level of increasing education - no education, primary, secondary, and tertiary-was associated with an increase of 1.3 points on the PEKS ( $\beta$ 1.3, SE 0.48, $p=0.008$ ). Each increase of one point on the counseling composite score was associated with an increase of 1.4 points on the PEKS ( $\beta$ 1.4, SE 0.3, $p<0.001$ ). Compared to participants who did not receive any counseling, participants counseled on all four domains scored on average 5.2 


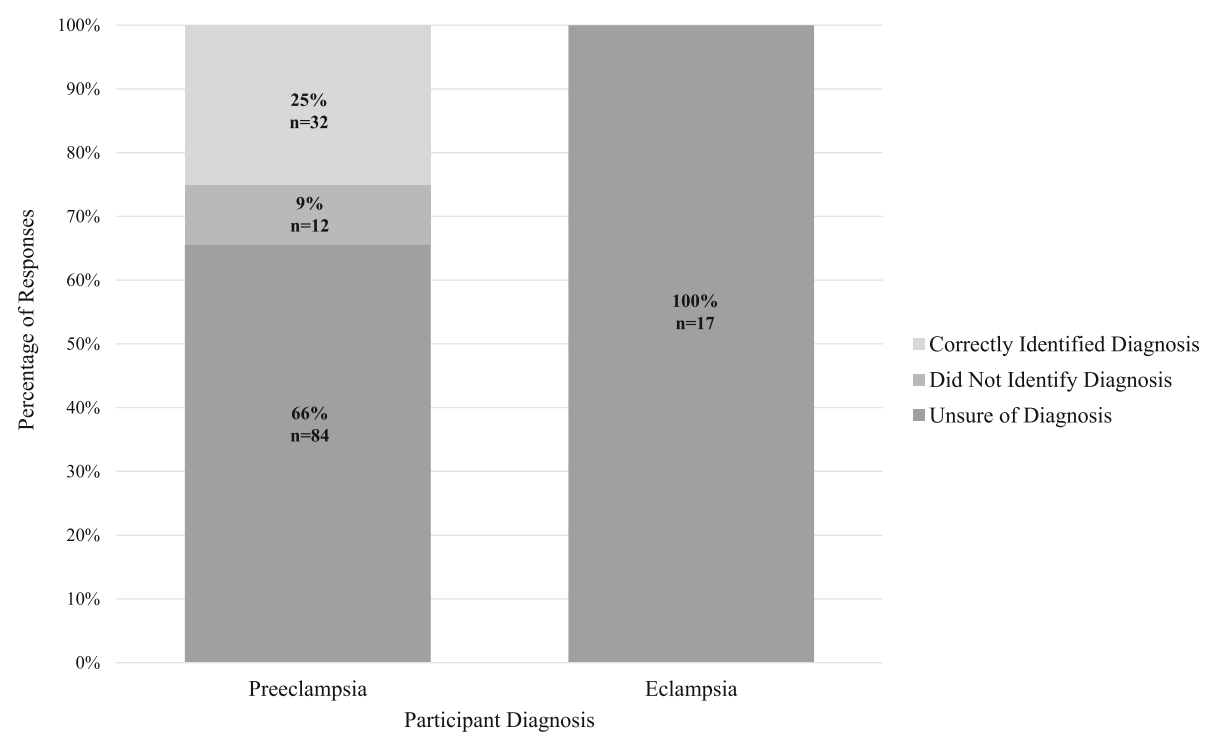

Fig. 2 Participants' Ability to Correctly Identify Diagnosis

points higher on the knowledge score (50\% increase). Figure 5 demonstrates the knowledge score for participants at each level of the counseling composite score, adjusted by the other variables in our final model.

\section{Discussion}

Our study explores the patient perspective of knowledge and counseling on preeclampsia/eclampsia in an urban LMIC setting. Although 74\% of women recognized having a complication during their pregnancy, one-third of women reported receiving no counseling from a provider regarding their condition. The biggest gap in counseling appears to be counseling on causes of the condition, with more than two-thirds of participants reporting no counseling on causes. Even when women reported being counseled, a large proportion reported understanding less than half of the information provided. Seventy-three percent of participants reported not knowing what to do to prevent or improve their condition in future pregnancies. Out of 22 possible points on the knowledge assessment, the average knowledge score was 13. Our multivariate analysis demonstrated that after controlling for age, parity, and number of antenatal visits, a higher knowledge score was predicted by a higher level of education and an increased amount of direct provider counseling.

Consistent with findings from studies of pregnant women in the United States [16], elsewhere in Ghana [17], and in other LMICs [21-23], our study demonstrates a low level of knowledge about preeclampsia/ eclampsia. In the United States, $57 \%$ of participants reported being counseled on signs and symptoms of preeclampsia/eclampsia [16], compared to only $49 \%$ in our Ghanaian population. Importantly, our study population consisted of women with a recent clinical diagnosis of preeclampsia or eclampsia undergoing inpatient management of this complication of pregnancy. It is especially imperative for this particular population to have an adequate level of knowledge and understanding, as the condition has directly impacted their just completed pregnancies, may continue to impact their health in the postpartum period, and is more likely to recur in their future pregnancies. Our study demonstrated a significant relationship between provider counseling on preeclampsia and participants' knowledge score. This key relationship has not been extensively explored, but agrees with findings from the United States [16, 18]. Education level was also a significant predictor of knowledge score, which is concordant with other studies performed in Ghana [17] and the United States [18]. Other studies demonstrated that higher literacy, multiparity, and a history of preeclampsia in a prior pregnancy were predictive of knowledge scores [18]. These relationships were significant in our bivariate analysis, but were no longer significant in our adjusted final model.

In 2016, updated World Health Organization (WHO) guidelines increased the number of recommended antenatal visits from four to eight, with the goal of better preventing and managing pregnancy-related or concurrent disease and providing health education [25]. Of note, our study demonstrated that the number of attended antenatal visits did not correlate with a higher PEKS score. While direct provider counseling increased a participant's PEKS score, more frequent antenatal visits 
Table 2 Knowledge Assessment

\begin{tabular}{|c|c|}
\hline Assessment & Participants $(n=150)$ \\
\hline \multicolumn{2}{|c|}{$\begin{array}{l}\text { Do you feel like you understand your condition well enough to explain } \\
\text { it to someone else? }\end{array}$} \\
\hline Yes & $57(38.3)$ \\
\hline No & $75(50.3)$ \\
\hline I don't know & $17(11.4)$ \\
\hline \multicolumn{2}{|c|}{$\begin{array}{l}\text { Do you know what to do in future pregnancies to prevent this } \\
\text { condition or improve upon its outcome? }\end{array}$} \\
\hline Yes & $40(27.0)$ \\
\hline No & $84(56.8)$ \\
\hline I don't know & $24(16.2)$ \\
\hline \multicolumn{2}{|c|}{ Who helped you the most with understanding your condition? } \\
\hline Doctor & $54(36.7)$ \\
\hline Midwife & $32(21.8)$ \\
\hline Nurse & $3(2.0)$ \\
\hline Family member & $8(5.4)$ \\
\hline Other & $5(3.4)$ \\
\hline None of the above & $45(30.6)$ \\
\hline \multicolumn{2}{|l|}{ When did you first hear about preeclampsia? } \\
\hline During pregnancy & $54(38.6)$ \\
\hline Month of pregnancy ${ }^{\mathrm{a}}$ & $6.65 \pm-1.74(2-9)$ \\
\hline I never heard about it & $86(61.4)$ \\
\hline \multicolumn{2}{|c|}{ How serious of a health issue do you think preeclampsia is? } \\
\hline Not at all serious & $5(3.5)$ \\
\hline Somewhat serious & $26(17.9)$ \\
\hline Very serious & 49 (33.8) \\
\hline Extremely serious, even life-threatening & $62(42.8)$ \\
\hline I don't know & $3(2.1)$ \\
\hline Preeclampsia/Eclampsia Knowledge Score ${ }^{a}$ & $13.1 \pm-4.5(2-21)$ \\
\hline
\end{tabular}

Data presented as $\mathrm{n}(\%)$ unless otherwise noted

Mean \pm SD (Range: minimum value - maximum value)

did not. This finding suggests that while increasing the frequency of antenatal visits may be important for many reasons, addressing systemic barriers to effective patientprovider communication, education, and counseling is important to see meaningful change in patient knowledge. Regarding ANC attendance and patient knowledge, our study fills a gap in the literature, as there are few studies that examine women's knowledge of preeclampsia and its correlation to the number of antenatal care visits, especially when examined as a continuous variable in linear regression. Within sub-Saharan Africa, studies show that patient education level is linked to increased knowledge regarding preeclampsia [17] and birth preparedness and complication readiness [26]. One study concluded that ANC attendance increased participant knowledge of obstetric danger signs during pregnancy and childbirth by approximately 2.5 times; however, this study treated ANC attendance as a binary yes/no variable, preventing the examination of a doseresponse relationship between the number of ANC visits and knowledge. Additionally, this study demonstrated that most participants were only able to identify vaginal bleeding as an obstetric warning sign, while less than half were able to identify any of the symptoms of preeclampsia as an obstetric warning sign [27]. This finding is consistent with another study that demonstrated less than one-third of participants could identify preeclampsia-specific warning signs [26]. This suggests that current ANC practices may not provide education and counseling that is comprehensive of all dangerous pregnancy-related complications. Addressing this problem requires a multidisciplinary approach and patients may benefit from other WHO-recommended methods of antenatal education such as group antenatal visits and community-based education [25].

Our study fills an important gap in the literature by exploring multiple predictors of patient knowledge, evaluating patient comprehension of provider counseling, and assessing the role of counseling in patient knowledge of preeclampsia in a LMIC setting. Strengths of the study include being embedded within a larger randomized controlled trial, which allowed our study population to consist entirely of women whose recent pregnancies were complicated by preeclampsia or eclampsia. To our knowledge, this is the first study of its kind to assess knowledge in this key targeted population. Participant knowledge of preeclampsia was assessed using a previously validated objective assessment created by the Preeclampsia Foundation [16], modified to the local context after extensive pilot testing. Although performed at a single site, the Korle Bu Teaching Hospital provides care for a wide range of attendants and referral patients from Ghana's capital city of Accra, as well as surrounding peri-urban and rural areas-supporting generalizability across Ghana. Diversity of participants is reflected in the range of age, language, education level, and number of ANC visits represented by our sample.

Limitations include challenges with language and translation, particularly because there is no direct Twi/ Akan translation of "preeclampsia" or "eclampsia." A pilot period, with feedback from patients and healthcare providers, was utilized to standardize translation of English questions into Twi/Akan. However, nuanced differences in translation may persist, causing bias between participants who completed the survey in English versus in Twi/Akan. Survey questions were verbally presented by a research assistant in the participant's language of choice to minimize limitations with literacy. Interviews were completed in an inpatient hospital setting, with potential for participants to be hesitant to respond 

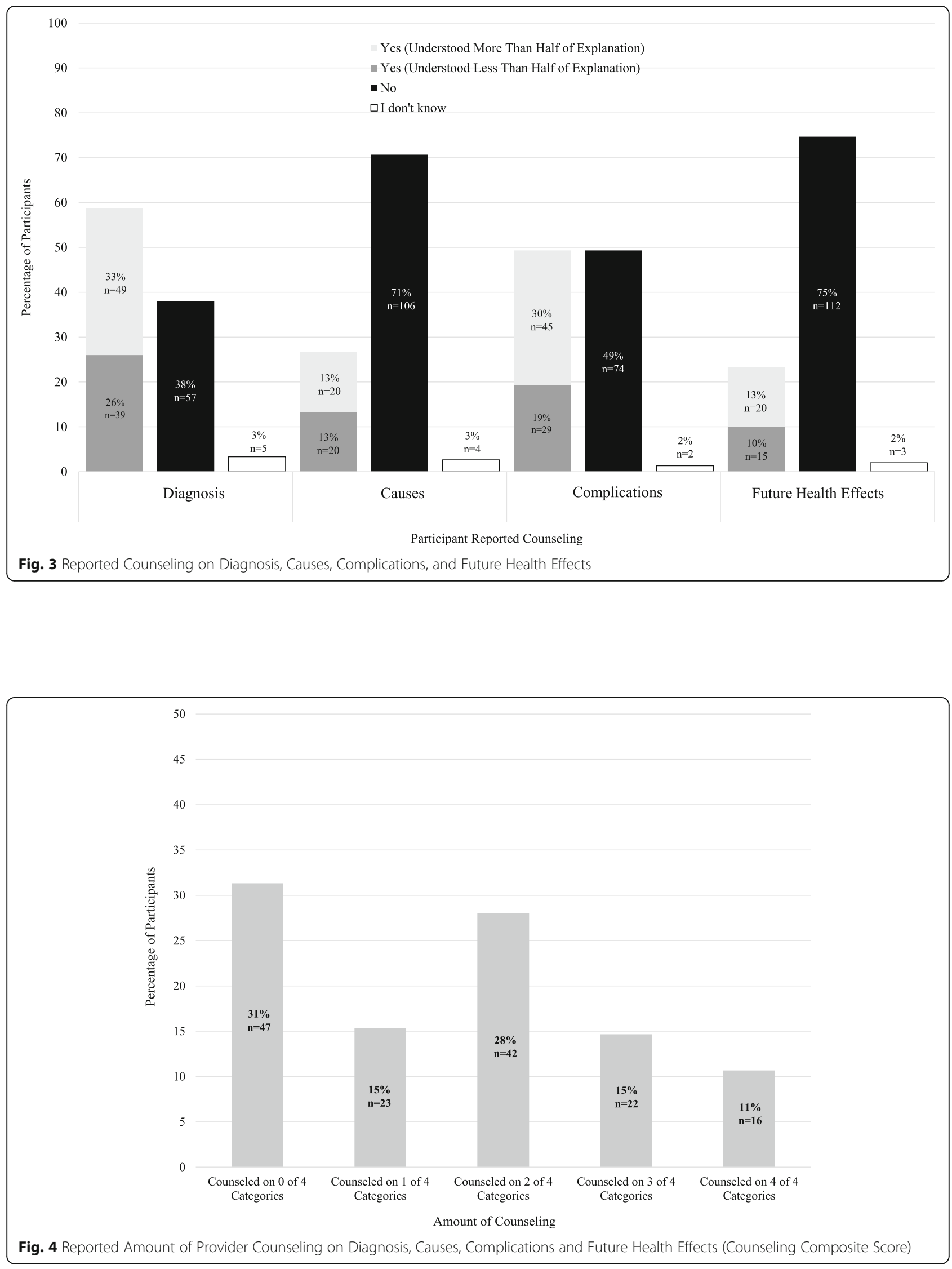
Table 3 Preeclampsia/Eclampsia Knowledge Score Bivariate Analysis

\begin{tabular}{|c|c|c|c|c|}
\hline \multirow[t]{2}{*}{ Factor } & \multicolumn{4}{|c|}{ Preeclampsia/Eclampsia Knowledge Score } \\
\hline & Mean \pm SD & $\beta$ & $95 \% \mathrm{Cl}$ & $p$-value \\
\hline \multicolumn{5}{|l|}{ Demographic Characteristics } \\
\hline \multicolumn{5}{|l|}{ Age, years } \\
\hline$<20$ & $5.60 \pm-3.65$ & -8.95 & $-12.95--4.95$ & $<0.001$ \\
\hline $20-24$ & $12.01 \pm-3.37$ & -2.49 & $-4.88--0.11$ & 0.041 \\
\hline $25-29$ & $12.83 \pm-3.98$ & -1.69 & $-3.65--0.26$ & 0.088 \\
\hline $30-34$ & $14.54 \pm-4.35$ & REF & REF & REF \\
\hline $35-39$ & $12.63 \pm-4.77$ & -1.91 & $-3.77--0.06$ & 0.044 \\
\hline$\geq 40$ & $14.9 \pm-4.51$ & 0.35 & $-2.62-3.33$ & 0.815 \\
\hline \multicolumn{5}{|l|}{ Main Language Used for Healthcare } \\
\hline English & $15.21 \pm-3.11$ & 2.75 & $1.03-4.47$ & 0.002 \\
\hline Twi & $12.46 \pm 4.70$ & REF & REF & REF \\
\hline \multicolumn{5}{|l|}{ Highest Level of Completed Education } \\
\hline None & $7.00 \pm 0.00$ & -4.61 & $-13.12-3.88$ & 0.285 \\
\hline Primary & $11.61 \pm-4.75$ & REF & REF & REF \\
\hline Secondary & $13.49 \pm-4.23$ & 1.87 & $0.19-3.56$ & 0.030 \\
\hline Tertiary & $15.49 \pm-3.27$ & 3.87 & $2.18-5.56$ & $<0.001$ \\
\hline \multicolumn{5}{|l|}{ Clinical Diagnosis } \\
\hline Preeclampsia & $13.18 \pm-4.39$ & REF & REF & REF \\
\hline Eclampsia & $12.18 \pm-5.64$ & -1.00 & $-3.32-1.31$ & 0.392 \\
\hline \multicolumn{5}{|l|}{ Parity $^{a}$} \\
\hline Primiparous & $12.31 \pm-4.39$ & REF & REF & REF \\
\hline Multiparous & $13.5 \pm-4.36$ & 1.20 & $-0.32-2.71$ & 0.120 \\
\hline \multicolumn{5}{|l|}{ Primary Caregiver During Pregnancy } \\
\hline Specialist obstetrician/gynecologist & $14.14 \pm-4.15$ & 1.54 & $-0.04-3.12$ & 0.056 \\
\hline Medical officer (non-obstetrician) & $17.33 \pm-2.24$ & 4.73 & $1.78-7.69$ & 0.002 \\
\hline Midwife & $12.60 \pm-4.37$ & REF & REF & REF \\
\hline Other & $10.0 \pm 0.00$ & -2.60 & $-11.11-5.91$ & 0.547 \\
\hline None & $8.00 \pm 5.63$ & -4.60 & $-7.92--1.28$ & 0.007 \\
\hline \multicolumn{5}{|c|}{ Number of Antenatal Appointments Attended ${ }^{a}$} \\
\hline $0-3$ & $12.69 \pm-5.29$ & REF & REF & REF \\
\hline$\geq 4$ & $13.21 \pm-4.23$ & 0.52 & $-1.11-2.16$ & 0.529 \\
\hline \multicolumn{5}{|l|}{ Diagnosis of Chronic Hypertension } \\
\hline Yes & $14.88 \pm-3.71$ & 2.32 & $0.59-4.06$ & 0.009 \\
\hline No & $12.56 \pm-4.63$ & REF & REF & REF \\
\hline \multicolumn{5}{|l|}{ Previous Preeclampsia/Eclampsia } \\
\hline Yes & $16.10 \pm-4.04$ & 3.25 & $0.35-6.15$ & 0.028 \\
\hline No & $12.85 \pm-4.51$ & REF & REF & REF \\
\hline \multicolumn{5}{|l|}{ Previous Gestational Hypertension } \\
\hline Yes & $12.91 \pm-4.50$ & -0.17 & $-2.99-2.65$ & 0.905 \\
\hline No & $13.08 \pm-4.56$ & REF & REF & REF \\
\hline \multicolumn{5}{|c|}{ Previous Hypertensive Disorder of Pregnancy } \\
\hline Yes & $14.43 \pm-4.49$ & 1.58 & $-0.52-3.69$ & 0.139 \\
\hline No & $12.84 \pm-4.53$ & REF & REF & REF \\
\hline
\end{tabular}


Table 3 Preeclampsia/Eclampsia Knowledge Score Bivariate Analysis (Continued)

\begin{tabular}{|c|c|c|c|c|}
\hline \multirow[t]{2}{*}{ Factor } & \multicolumn{4}{|c|}{ Preeclampsia/Eclampsia Knowledge Score } \\
\hline & Mean \pm SD & $\beta$ & $95 \% \mathrm{Cl}$ & $p$-value \\
\hline \multicolumn{5}{|l|}{ Provider Counseling } \\
\hline \multicolumn{5}{|c|}{ Did your health caregiver provide information about your diagnosis? } \\
\hline Yes & $14.65 \pm-3.56$ & 3.83 & $2.47-5.18$ & $<0.001$ \\
\hline No & $10.82 \pm-4.85$ & REF & REF & REF \\
\hline \multicolumn{5}{|c|}{ Did your health caregiver provide information about your causes? } \\
\hline Yes & $15.38 \pm-3.34$ & 3.15 & $1.57-4.73$ & $<0.001$ \\
\hline No & $12.23 \pm-4.64$ & REF & REF & REF \\
\hline \multicolumn{5}{|c|}{ Did your health caregiver provide information about your complications? } \\
\hline Yes & $14.92 \pm-2.99$ & 3.66 & $2.31-5.00$ & $<0.001$ \\
\hline No & $11.26 \pm-5.05$ & REF & REF & REF \\
\hline \multicolumn{5}{|c|}{ Did your health caregiver provide information about your future health effects? } \\
\hline Yes & $15.54 \pm-2.98$ & 3.23 & $1.57-4.89$ & $<0.001$ \\
\hline No & $12.31 \pm-4.67$ & REF & REF & REF \\
\hline \multicolumn{5}{|l|}{ Provider Counseling Composite Score } \\
\hline Counseled on 0 of 4 components & $9.78 \pm-4.93$ & REF & REF & REF \\
\hline Counseled on 1 of 4 components & $13.52 \pm-4.04$ & 3.73 & $1.76-5.71$ & REF \\
\hline Counseled on 2 of 4 components & $14.00 \pm-3.45$ & 4.21 & $2.57-5.86$ & REF \\
\hline Counseled on 3 of 4 components & $15.41 \pm-2.44$ & 5.62 & $3.62-7.62$ & REF \\
\hline Counseled on 4 of 4 components & $16.38 \pm-3.01$ & 6.59 & $4.35-8.83$ & REF \\
\hline
\end{tabular}

negatively about counseling from their healthcare providers. However, research assistants had no role in patient care and the informed consent process outlined standards of confidentiality and anonymity. Additional limitations include recall bias, where participants with higher health literacy and more knowledge about preeclampsia may recall that more provider counseling was performed. Recall bias was minimized by not disclosing correct responses to the knowledge questions until the entire survey was complete. Additionally, recall bias

Table 4 Preeclampsia/Eclampsia Knowledge Score Multivariate Analysis

\begin{tabular}{llll}
\hline Model $^{\mathbf{a}}$ & $\boldsymbol{\beta}$ & $\mathbf{9 5 \%} \mathbf{C l}$ & $\boldsymbol{p}$-value \\
\hline Age & 0.05 & $-0.08-0.17$ & 0.453 \\
Language of Healthcare & -0.25 & $-2.12-1.62$ & 0.790 \\
Education Level & 1.29 & $0.34-2.23$ & 0.008 \\
Parity & 0.24 & $-0.22-0.71$ & 0.306 \\
Antenatal Care (category) & 0.36 & $-1.03-1.75$ & 0.609 \\
Diagnosis of Chronic Hypertension & 1.29 & $-0.25-2.83$ & 0.101 \\
Previous Preeclampsia/Eclampsia & 0.77 & $-1.77-3.31$ & 0.550 \\
Counseling Composite Score & 1.35 & $0.87-1.84$ & $<0.001$ \\
\hline R squard
\end{tabular}

${ }^{\mathrm{a}} \mathrm{R}$ squared $=0.36$ could have unequally affected patients diagnosed with eclampsia, especially regarding provider counseling during antenatal and pre-delivery care. Lastly, additional studies are required to assess retention of knowledge over time and changes in knowledge after a patient's outpatient postpartum visit.

\section{Conclusions}

Our study highlights the importance of providerbased counseling in improving knowledge about preeclampsia. We demonstrate that average knowledge about preeclampsia is low, and increased counseling by healthcare providers is associated with higher knowledge scores. Knowledge about preeclampsia is important so patients may identify warning symptoms of new or worsening disease, improve healthcareseeking behavior, and make informed healthcare decisions [15]. Given significant risk of recurrence in subsequent pregnancies, patient knowledge about causes, prevention, and recurrence of preeclampsia can promote early prenatal visits and hospital deliveries for these high-risk women. While we acknowledge there are many systemic barriers that can make counseling difficult for providers, improving counseling and ensuring that patients understand their diagnosis of preeclampsia/eclampsia is likely to improve outcomes. 
20

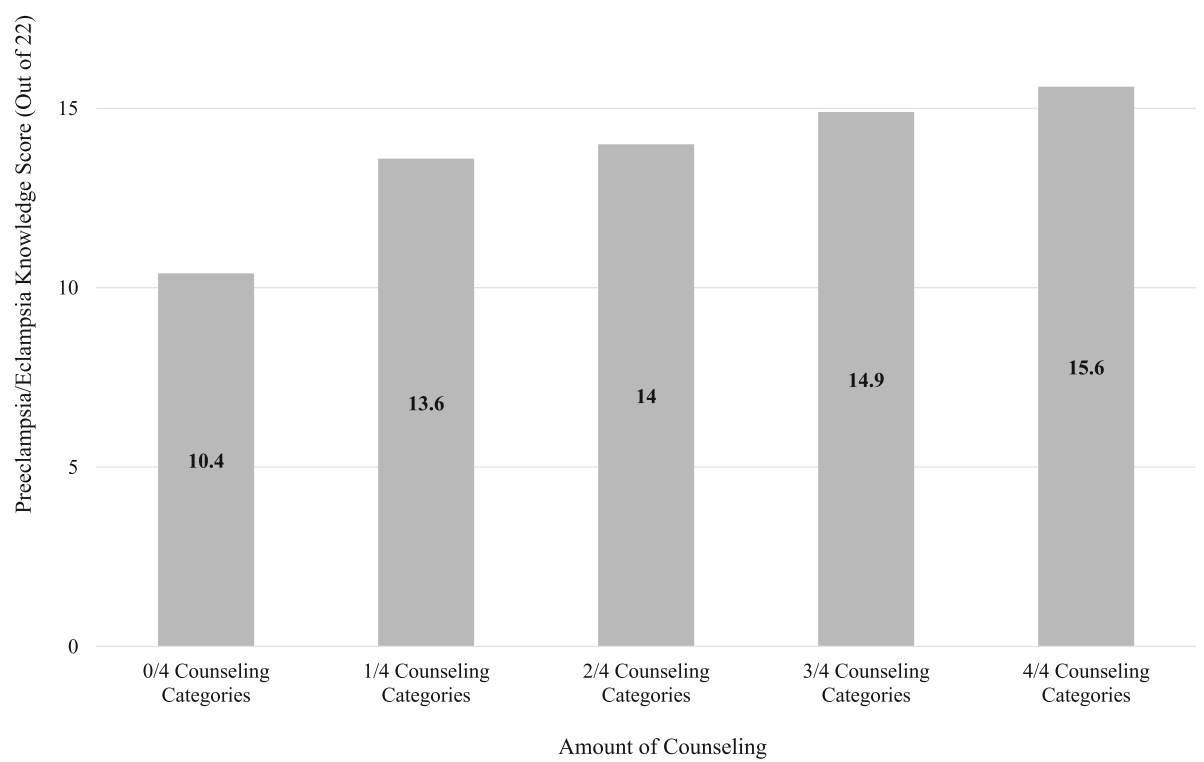

Fig. 5 Impact of Provider Counseling on Preeclampsia/Eclampsia Knowledge Assessment Score

Findings from this research have significant implications for developing educational interventions to address knowledge gaps and improve patient counseling. Additional research is needed to evaluate the impact of educational interventions on patient knowledge, and to explore the relationship between patient knowledge and maternal and neonatal outcomes.

\section{Supplementary information}

Supplementary information accompanies this paper at https://doi.org/10. 1186/s12884-020-03316-w.

Additional file 1: Survey questions. Part I (24 questions) and Part II (10 questions) of the survey verbally administered to study participants.

\section{Abbreviations}

PEKS: Preeclampsia/Eclampsia Knowledge Score; LMIC: Low- and middleincome country; ANC: Antenatal care; KBTH: Korle Bu Teaching Hospital; WHO: World Health Organization.

\section{Acknowledgements}

The authors would like to acknowledge Andrews Owusu for significant contributions to data collection and Sarah Block for editorial and formatting assistance.

\section{Authors' contributions}

All listed authors meet criteria for authorship. ERL, CAM, TB, and SAO made substantial contributions to conception and design of the work. AJ, ERL, and CAM were significantly involved with data acquisition and analysis. All authors drafted and revised the work, approved the submitted version, and agreed to be personally accountable for their own contributions to the work.

\section{Funding}

This study was supported by two funding sources: The Women's Health Innovation Grant from the Women's Health Leadership Board and a
Fulbright-Fogarty grant from the Fogarty International Center of the National Institutes of Health under Award Number D43TW009345. The content is solely the responsibility of the authors and does not necessarily represent the official views of the National Institutes of Health.

\section{Availability of data and materials}

The datasets used and/or analyzed during the current study are available from the corresponding author on reasonable request.

\section{Ethics approval and consent to participate}

Ethical approval was granted by the Scientific and Technical Committee of the Korle Bu Teaching Hospital (KBTH-IRB 00096/2018) and the University of Michigan Institutional Review Board (HUM00139104). Participants completed written consent at the time of enrollment.

\section{Consent for publication}

Not applicable.

\section{Competing interests}

The authors declare that they have no competing interests.

\section{Author details}

${ }^{1}$ University of Massachusetts Medical School, 55 N. Lake Ave, Worcester, MA 01655, USA. ${ }^{2}$ University of Ghana School of Medicine and Dentistry, Slater Avenue, Accra, Ghana. ${ }^{3}$ Department of Obstetrics \& Gynaecology, Korle Bu Teaching Hospital, Guggisberg Avenue, Accra, Ghana. ${ }^{4}$ Global REACH, University of Michigan Medical School, 1301 Catherine St, Ann Arbor, Ml 48109, USA. ${ }^{5}$ Department of Obstetrics \& Gynecology, University of Michigan Medical School, 1500 E. Medical Center Dr, Ann Arbor, MI 48109, USA.

Received: 28 July 2020 Accepted: 6 October 2020

Published online: 15 October 2020

\section{References}

1. Duley L. The global impact of pre-eclampsia and eclampsia. Semin Perinatol. 2009;33(3):130-7.

2. Recommendations WHO. For prevention and treatment of pre-Eclampsia and Eclampsia. Geneva: World Health Organization; 2013. 
3. Adu-Bonsaffoh K, Oppong SA, Binlinla G, Obed SA. Maternal deaths attributable to hypertensive disorders in a tertiary hospital in Ghana. Int J Gynaecol Obstet. 2013;123(2):110-3.

4. Acquah-Arhin R, Kwawukuwe EY. Trends in eclampsia at Korle Bu Teaching Hospatal, Accra Ghana. Niger J Clin Pract. 2003;6(1):1-4.

5. Goldenberg RL, EM MC. It Takes a System: Magnesium Sulfate for Prevention of Eclampsia in a Resource-Limited Community Setting. Global Health Sci Pract. 2019; 16 [cited 2019 Dec 14]; Available from: http://www. ghspjournal.org/content/early/2019/09/16/GHSP-D-19-00261.abstract.

6. Ronsmans C, Campbell O. Quantifying the fall in mortality associated with interventions related to hypertensive diseases of pregnancy. BMC Public Health. 2011;11(Suppl 3):S8

7. American College of Obstetrics and Gynecology. Hypertension in Pregnancy: Executive Summary. Obstet Gynecol. 2013;122(5):1122.

8. Practice Bulletin No ACOG. 202: gestational hypertension and preeclampsia. Obstet Gynecol. 2019;33(1):e1-e25.

9. Integrated management of pregnancy and childbirth (Impac). Provision of effective antenatal care: WHO; 2006. [cited 7 July 2020]; Available from: https://www.who.int/reproductivehealth/publications/maternal_perinatal_ health/effective_antenatal_care.pdf.

10. Chalmers B, Mangiaterra V, Porter R. WHO principles of perinatal care: the essential antenatal, perinatal, and postpartum care course. Birth. 2001;28(3): 202-7.

11. Fiscella K. Does prenatal care improve birth outcomes? A critical review. Obstet Gynecol. 1995:85(3):468-79.

12. Alexander GR, Kotelchuck M. Assessing the role and effectiveness of prenatal care: history, challenges, and directions for future research. Public Health Rep. 2001;116(4):306-16.

13. Haelterman E, Qvist R, Barlow P, Alexander S. Social deprivation and poor access to care as risk factors for severe pre-eclampsia. Eur J Obstet Gynecol Reprod Biol. 2003;111(1):25-32.

14. Adams RJ. Improving health outcomes with better patient understanding and education. Risk Manag Healthc Policy. 2010;3:61-72.

15. Wallis AB, Tsigas EZ, Saftlas AF, Sibai BM. Prenatal education is an opportunity for improved outcomes in hypertensive disorders of pregnancy: results from an internet-based survey. J Matern Fetal Neonatal Med. 2013; 26(16):1565-7

16. Wilkinson J, Cole G. Preeclampsia knowledge among women in Utah. Hypertens Pregnancy. 2018;37(1):18-24.

17. Fondjo LA, Boamah VE, Fierti A, Gyesi D, Owiredu E-W. Knowledge of preeclampsia and its associated factors among pregnant women: a possible link to reduce related adverse outcomes. BMC Pregnancy Childbirth. 2019; 19(1):456.

18. You WB, Wolf M, Bailey SC, Pandit AU, Waite KR, Sobel RM, et al. Factors associated with patient understanding of preeclampsia. Hypertens Pregnancy. 2012;31(3):341-9.

19. Schrauben SJ, Wiebe DJ. Health literacy assessment in developing countries: a case study in Zambia. Health Promot Int. 2017;32(3):475-81.

20. Finlayson K, Downe S. Why do women not use antenatal services in lowand middle-income countries? A meta-synthesis of qualitative studies. PLoS Med. 2013;10(1):e1001373.

21. Daniel EE, Ambrose B, Moses DA, Karimah MR, Nganda P. Determination, knowledge and prevalence of pregnancy-induced hypertension/eclampsia among women of childbearing age at same district Hospital in Tanzania. Int J Med Med Sci. 2018;10(2):19-26.

22. Savage AR, Hoho L. Knowledge of pre-eclampsia in women living in Makole Ward, Dodoma, Tanzania. Afr Health Sci. 2016:16(2):412-9.

23. Zuo TC, Teng SP, Keng SL, btJummaat F. Knowledge of preeclampsia among antenatal women in a tertiary referral teaching hospital. Malaysian J Nurs. 2016;7(2):8-13.

24. Beyuo T, Lawrence E, Langen ES, Oppong SA. Open-labelled randomised controlled trial of 12 hours versus 24 hours modified Pritchard regimen in the management of eclampsia and pre-eclampsia in Ghana (MOPEP study): study protocol. BMJ Open. 2019;9(10):e032799.

25. Recommendations WHO. On antenatal Care for a Positive Pregnancy Experience. Geneva: World Health Organization; 2016.

26. Florence M, Atuhaire C, Nkfusai CN, Shirinde J, Cumber SN. Knowledge and practice of birth preparedness and complication readiness among pregnant women attending antenatal clinic in Openzinzi Hciii, Adjumani District, Uganda. Pan Afr Med J. 2019:34:46.
27. Bogale D, Markos D. Knowledge of obstetric danger signs among child bearing age women in Goba district, Ethiopia: a cross-sectional study. BMC Pregnancy Childbirth. 2015;15:77.

\section{Publisher's Note}

Springer Nature remains neutral with regard to jurisdictional claims in published maps and institutional affiliations.
Ready to submit your research? Choose BMC and benefit from:

- fast, convenient online submission

- thorough peer review by experienced researchers in your field

- rapid publication on acceptance

- support for research data, including large and complex data types

- gold Open Access which fosters wider collaboration and increased citations

- maximum visibility for your research: over $100 \mathrm{M}$ website views per year

At $\mathrm{BMC}$, research is always in progress.

Learn more biomedcentral.com/submissions 